\title{
Time-dependent effect of selenium supplementation on the relationship between selenium concentrations in whole blood and plasma of sheep
}

\author{
J.B.J. van Ryssen ${ }^{\mathrm{a} *}$, R.J. Coertze ${ }^{\mathrm{a}}$, M.F. Smith ${ }^{\mathrm{b}}$ \\ a Department of Animal \& WildlifeSciences, University of Pretoria, Pretoria 0002, South Africa \\ ${ }^{\mathrm{b}}$ Stats4science, P.O. Box 50505, Moreleta Village0097, Pretoria, South Africa \\ * Corresponding author. Tel.: +27 12 4206017; fax: +27 12 4203290. E-mail address: jvryssen@up.ac.za (J.BJ. van Ryssen).
}

\begin{abstract}
A B S T R A C T
The ratio between selenium (Se) concentrations in pairs of plasma and whole blood of sheep after commencement of Se supplementation was calculated from data obtained from 10 independent investigations. The diets in the studies consisted of a variety of ingredients, from the individual feeding of feedlot diets to grazing trials on Se-deficient pastures. Means from 51 treatments, derived from 179 collections at various stages after commencement of Se supplementation, were used to calculate the ratios. In one study it was found that plasma Se concentration reached steady-state within 4 days of commencement, while Se in whole blood reached steady-state only at the collection 60 days after supplementation commenced. Using the 179 pairs, the ratio of whole blood and plasma stabilized at about 50 days after commencement when inorganic Se was supplemented, and at about 60-70 days when the Se was in the organic form. The ratios stabilized when they were between $2: 1$ and 3:1, and remained practically constant from 50 days post onset of supplementation, when plasma Se constituted 0.445 of whole blood Se concentration for the inorganic Se source and 0.410 when the Se source was organic. It was concluded that after commencement of Se intake, plasma Se concentration remains relatively constant from within 4 days of onset, while whole blood Se concentration apparently reaches steady-state only after approximately 50 days. Before 50 days, whole blood Se seems not to be reliable to predict the Se status of an animal. In a situation where Se intake is stable and Se requirements do not fluctuate, a bloodplasma ratio of between 2:1 and 3:1 would be a guideline to indicate that whole blood Se and plasma Se concentrations could both be used to assess the Se status of sheep.
\end{abstract}

Keywords: Sheep; Diagnosis; Selenium status ; Steady-state; Whole blood Se: Plasma Se ratio

\section{Introduction}

The concentration of selenium (Se) in whole blood, plasma/serum and the liver of animals, as well as glutathione peroxidase (GSH-Px) activity in the erythrocytes, is widely used by diagnostic laboratories to predict the Se status of animals (Gerloff, 1992). Such values have been published in tables and guidelines, using criteria such as deficient, marginal, adequate, high and toxic ranges (Puls, 1994; Kincaid, 1999, 2008; Underwood and Suttle, 1999). Such a classification implies that there should be a relationship between the criteria of Se status. For example, deficiency can be expected within specific ranges of concentrations of Se in serum/plasma, whole blood and the liver.

One of the most convenient animal tissues to sample for diagnostic purposes is blood on which Se concentrations can be measured in plasma/serum and in whole blood.

Glutathione peroxidase activity in haemoglobin or erythrocytes can be measured, but the repeatability of results between laboratories is low (Gerloff, 1992). Therefore, this assay is used less frequently.

In the early 1990s controversy was rife in the scientific literature between laboratories as to whether plasma/serum Se or whole blood Se was the preferred fluid to use in assessing the Se status of animals (Maas et al., 1992, 1993; Thompson and Ellison, 1993). For instance, Maas et al. (1993) pointed out some limitations in using serum Se concentrations, viz. the unknown effect of haemolysis and the greater variability in serum Se values in relation to blood Se values, especially at low concentrations. This issue was not really resolved and laboratories world-wide still use whole blood Se, or plasma/serum Se, or both for diagnostic purposes (Waldner et al., 1998).

It is well recognised that the information provided by whole blood Se status represents a different time frame in the nutritional history of the animal from plasma/serum Se concentrations (Waldner et al., 1998). Selenium concentration responds more slowly to changes in Se intake in whole blood than in plasma/serum, because Se is incorporated in erythrocytes at the time of erythropoiesis (Nicholson et al., 1991), and changes very little over the lifespan of the cell. A complete response in whole blood to Se supplementation would require a timespan equal to the lifespan of the erythrocyte, which in cattle can range from 135 to162 days and in sheep from 131 to 157 days (Kaneko, 1980), while Wright (1965) recorded an average of 157 days in sheep. On the other hand, Se concentrations in plasma/serum responded more quickly to changes in Se intake. This demonstrates why plasma 
concentrations would reflect more accurately the current level of Se intake of an animal and whole blood Se over the long term (Gerloff, 1992; Maas et al., 1993; Thompson and Ellison, 1993; Whelan et al., 1994; Hall, 2006; Kincaid, 2008).

What is unclear from these arguments is exactly what is meant by short-term and long-term Se status. We were afforded the opportunity to use data collected from 10 experiments conducted under the supervision of the main author over approximately 12 years in which the Se concentrations were measured in both plasma and whole blood for the duration of the study. This enabled us to compare the relationship between whole Se and plasma Se and to observe how time after commencement of Se supplementation affected this relationship.

\section{Material and methods}

\subsection{Source of experimental data}

In a study by Cronjé (2004, unpublished results) blood and plasma samples were collected on day zero (presupplementation) and then on days 1,2,4,8,16,30,60 and 90 after commencement of supplementation. The results of the two treatments $(\mathrm{n}=11 /$ treatment) in which inorganic Se was supplemented are presented in Fig. 1. At the onset of the study, the Se concentration in whole blood was $56 \mathrm{ng} / \mathrm{g}$, suggesting a marginal deficiency (Puls, 1994), and the supplemented treatments consisted of high doses of Se, calculated to be $2.5 \mathrm{mg} \mathrm{Se} / \mathrm{kg}$ feed and $4 \mathrm{mg} \mathrm{Se} / \mathrm{kg}$ feed, from day 1 onwards.

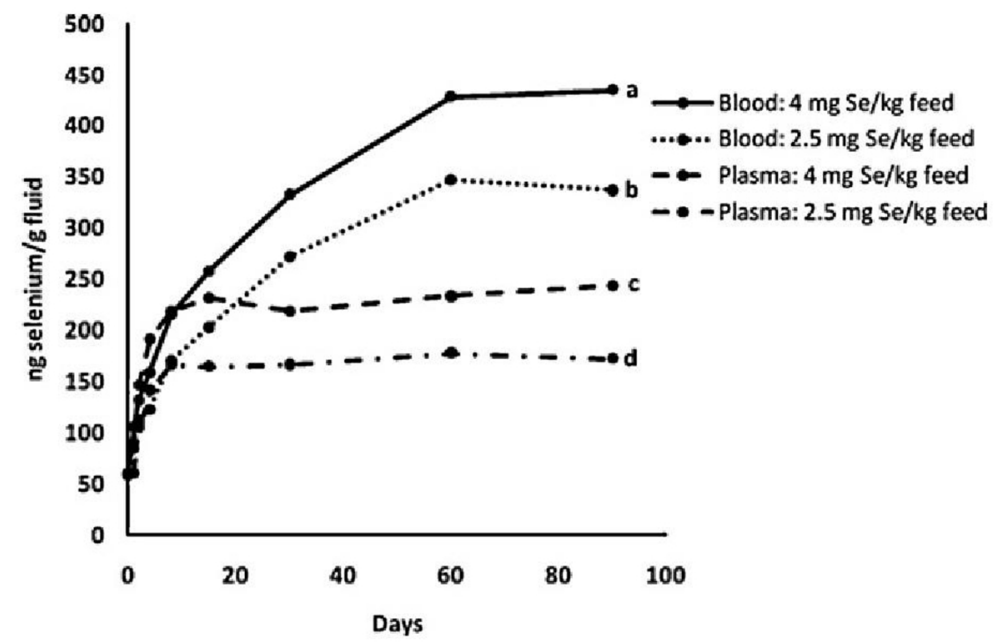

Fig. 1. Changes in selenium (Se) concentrations in plasma and whole blood after commencement of selenium supplementation. Means with different letters $(\mathrm{a}, \mathrm{b}, \mathrm{c}, \mathrm{d})$ differ at $P<0.0001$. From day 2 onwards differences in plasma Se concentrations between dietary levels of Se were significant at $P<0.001$. From day 8 onwards differences in whole blood Se concentrations between dietary levels of Se were significant at $P<0.001$.

Table 1

Experiments used in calculations where selenium (Se) concent rations were measured in both whole blood and plasma of sheep.

\begin{tabular}{|c|c|c|c|c|c|}
\hline Trial & Source of data & Duration (days) & Type of diet & Dietary levels of Se (mg/ $\mathrm{kg} \mathrm{DM})$ & $\begin{array}{l}\text { Sheep weight At } \\
\text { onset }(\mathrm{kg})\end{array}$ \\
\hline A & Mavimbela (2000) & 84 & $100,92.5,85 \%$ broiler litter $^{\mathrm{a}}$ & 0.68 & 42 \\
\hline B & Mavimbela (2000) & 44 & $100,92.5,85 \%$ broiler litter ${ }^{\mathrm{a}}$ & 0.66 & 35 \\
\hline C & Copper $\times \mathrm{Se} \times$ sulphur trial & 69 & Lamb finishing diet & $0.35,0.88,1.34$ & 23 \\
\hline D & Van Ryssen (1995) & 72 & $25 \%$ hay or $45 \%$ hay & $0.15,0.31,0.42,0.63$ & 28 \\
\hline E & Jansen van Rensburg (2000) & 150 & $72 \%$ hay, $28 \%$ concentrate & $0.38,1.01,1.80,6.40$ & 35 \\
\hline $\mathrm{F}$ & Cronjé (2004) & 90 & $100 \%$ hay & $0.073,2.50,4.00$ & 34 \\
\hline G & Hartmann (1994) & 61 & Lamb finishing diet & $0.30,1.50$ & 28 \\
\hline $\mathrm{H}$ & Grazing trial on kikuyu & 132 & Pasture $^{\mathrm{b}}$ & $0.034^{\mathrm{c}}, 0.065^{\mathrm{d}}$ & 25 \\
\hline I & Grazing trial 1 on rye grass & 80 & Pasture ${ }^{b}$ & $0.111^{c}, 0.485^{d}$ & 23 \\
\hline $\mathrm{J}$ & Grazing trial 2 on rye grass & 98 & Pasture $^{b}$ & $0.073^{\mathrm{c}}, 0.325^{\mathrm{d}}$ & 22 \\
\hline
\end{tabular}

a Survival diets.

b Treatments: Se fertilized, parenteral (long-acting Se product) (Van Ryssen et al., 1999).

${ }^{c}$ Mean of unfertilized grass.

d Mean of Se fertilized grass. 
In a further investigation the association between the Se concentrations in whole blood and plasma were calculated from data obtained from 10 independent trials (Table 1) in which the Se concentration in both whole blood and plasma were determined. The ratios between whole blood Se and plasma Se concentrations were calculated for all data at all the stages after commencement of Se inclusion in the diets. The total number of pairs was 179 (Table 2), subdivided into source of selenium and number of days after commencement of Se supplementation. When the original studies were conducted, ethical approval was obtained at the institutions where the studies were conducted.

In all the studies, Merino type sheep were used, ranging in age from 5 months to $c a$. 18 months. Dietary levels ranged from $0.07 \mathrm{mg} \mathrm{Se} / \mathrm{kg}$ to $6.4 \mathrm{mg} \mathrm{Se} / \mathrm{kg} \mathrm{DM}$ (Table 1).

In seven of the trials, the sheep were fed individually in pens, and in three trials weaned lambs were kept on pastures. The duration of the trials ranged from 44 to 150 days (Table 1). The individually fed animals received constant levels of dietary Se per treatment for the duration of the study, though the diets between trials differed substantially in ingredient composition (Table 1). It was not possible to establish the dietary Se level in the grazing trials because some treatments entailed Se fertilization of the pasture and parenteral supplementation of Se, though the blood Se:plasma Se ratios were used in the calculations.

Pre-experimental treatments varied. In some cases animals were depleted, others started with low selenium reserves; and in some studies an adaptation period was used. Measurements on whole blood and plasma collected at day zero therefore represented a pre-experimental feeding regimen, and were not included in the calculations.

\subsection{Sources of selenium}

In most of the experimental treatments, inorganic Se, as sodium selenite (NaSe2O3), was used as the supplement (Table 2). However, the raw diet ingredients did contain Se, presumably in an organic form. This natural Se would have contributed something to the results. In some treatments, organic sources of selenium were supplemented, viz. a commercially available selenoyeast or natural organic Se in Se fertilized pasture and in the raw feed ingredients (Table 2). Since the organic sources differed, factors such as ruminal degradation of the organic Se might have differed between sources.

\section{Table 2}

Source of data, number of treatments used, number of days when blood was collected according to form of selenium, as used in preparing the graphs in Fig. 2.

\begin{tabular}{|c|c|c|c|c|c|c|}
\hline \multirow[t]{2}{*}{ Study } & \multicolumn{3}{|c|}{ Inorganic selenium source } & \multicolumn{3}{|c|}{ Organic selenium source } \\
\hline & No of treatments & No of days ${ }^{\mathrm{a}}$ collected & No of collections & No of treatments & No of days ${ }^{a}$ collected & No of collections \\
\hline A & 3 & 3 & 9 & & & \\
\hline B & 3 & 2 & 6 & & & \\
\hline C & 12 & 5 & 60 & & & \\
\hline $\mathrm{D}$ & 4 & 3 & 12 & 4 & 3 & 12 \\
\hline $\mathrm{E}$ & 3 & 1 & 3 & 4 & 1 & 4 \\
\hline $\mathrm{F}^{\mathrm{b}}$ & 2 & 6 & 12 & & & \\
\hline G & 8 & 3 & 24 & & & \\
\hline $\mathrm{H}^{\mathrm{b}}$ & 1 & 5 & 5 & 1 & 5 & 5 \\
\hline$I^{\mathrm{b}}$ & 1 & 4 & 4 & 2 & 4 & 8 \\
\hline $\mathrm{J}^{\mathrm{b}}$ & 1 & 5 & 5 & 2 & 5 & 10 \\
\hline Total & 38 & & 140 & 13 & & 39 \\
\hline
\end{tabular}

a Data from pre-experimental collections excluded.

b Data from control treatments excluded.

\subsection{Sample preparation and analytical procedures}

In all trials, lithium heparin was used as the anti-coagulant, though whole blood Se concentration was not corrected for packed cell volume (PCV). Visible haemolysed plasma samples were rejected. In the chemical analysis, blood and plasma samples were weighed and expressed on a weight basis because this was found to be more repeatable than measuring blood and plasma volume. In the first number of experiments the Koh and Benson (1983) fluorometric technique was used for the Se assay, and this was followed by the continuous hydride generation atomic absorption method, read at anabsorbency of $196 \mathrm{~nm}$ and lamp energy of $16 \mathrm{~mA}$. To verify the accuracy of the Se assay, internal laboratory bovine livers, calibrated against a bovine liver sample (no. 1577b) from the National Institute of Standards and Technology (NIST), US Department of Commerce, Gaithersburg, MD, were used as standard reference material, and included in each batch of analyses.

\subsection{Statistical procedures}

In the first set of analysis (Fig. 1) data were analysed as a randomized block design with the GLM model (SAS, 2012) for the average effect over time. Means and standard errors were calculated and significant differences between means were determined by the Fischer's test (Samuels, 1989)

In measuring the whole blood to plasma Se ratios, the raw data from the original worksheets were used to calculate treatment means. In the statistical analysis, means from individual treatments and collections were regarded as independent. Non-linear regression analysis was applied to the blood to plasma ratio per source of Se to determine the exponential curve that best describes the trend in the data. The statistical program GenStat ${ }^{2}$ (Payne et al., 2011), was used for all data analyses. 


\section{Results and discussion}

\subsection{Selenium concentrations after commencement of supplementation}

The results of the two treatments from the Cronjé (2004), study in which Se was supplemented are presented in Fig. 1. At the onset of the study, the sheep were marginally deficient. In the two treatments the lambs received high doses of Se, $2.5 \mathrm{mg} \mathrm{Se} / \mathrm{kg}$ feed and $4 \mathrm{mg} \mathrm{Se} / \mathrm{kg}$ feed, from day 1 onwards. Under this specific situation (relatively low Se status and a high level of supplementation), plasma Se concentration shot up within the first day to surpass the concentration of Se in whole blood. However, in less than 4 days the Se concentration in plasma had reached a plateau, and remained practically constant for the duration of the 90-day experimental period, while whole blood Se concentration continued to increase and seemed to have reached a steady-state at day 60 .

From day 2 onwards the plasma Se concentrations between the two dietary levels of Se, $2.5 \mathrm{mg} / \mathrm{kg}$ and $4 \mathrm{mg} / \mathrm{kg}$ feed, were different $(\mathrm{P}<0.001)$, and from day 8 onwards the Se concentrations in blood between the two dietary levels of Se, $2.5 \mathrm{mg} / \mathrm{kg}$ and $4 \mathrm{mg} / \mathrm{kg}$ feed, were different $(\mathrm{P}<0.001)$.

Situations in which the Se concentration in plasma is higher than in whole blood have not been reported frequently. Boldizarova et al. (2003) reported a dramatic increase in the plasma Se content of sheep that received an intravenous injection of sodium selenite. Langlands et al. (1991) plotted the relationship between whole blood Se and plasma Se, and presented points where plasma Se concentrations were higher than those in whole blood. However, no explanation was suggested for this observation.

In many Se supplementation trials, a pre-experimental blood sample is taken and the second collection takes place only after an interval of two weeks or longer. Consequently, graphs are presented in which plasma/serum Se concentrations have apparently reached a steady-state by day 20 (Van Ryssen et al, 1989), have peaked by four weeks (Nicholson et al., 1991), (Hartmann and Van Ryssen, 1997), by 21 days (Van Ryssen et al, 1999) or within 14 days (Taylor, 2005). However, after the first collection at four weeks, over 52 weeks Cristaldi et al. (2005) recorded increasing concentrations of Se in the serum of sheep receiving inorganic Se. This was more pronounced at the higher dietary Se concentrations, which ranged from $0.2 \mathrm{mg} / \mathrm{kg}$ to $10 \mathrm{mg} / \mathrm{kg}$ than at the lower levels of intake. Since concentrations in Se levels of intake fluctuated, it is not clear whether and when steady-state in serum Se concentration had been reached in that study.

The graphs in Fig. 1 suggest that a steady-state in blood Se concentration was reached by day 60 after commencement of supplementation. However, Van Ryssen et al. (1989) reported that whole blood Se concentration of sheep continued to increase during the 112 days of their trial. In dairy cows, Knowles et al. (1999) found that steady-state had not been achieved by 133 days after commencement of supplementation.

In this study plasma Se reached a peak within 4 days and remained at a relatively constant concentration for 90 days. Cristaldi et al. (2005) stated that Se concentrations in serum generally reflect the level of dietary Se, as is evident from Fig. 1. Therefore, it could be concluded that plasma/serum Se concentrations would be an acceptable measure of predicting Se status of the animal at least from day 4 after supplementation commenced, and onwards. On the other hand, whole blood Se concentration had reached steady-state only when the 60-day samples were collected.

\subsection{Ratio between selenium in whole blood and plasma}

The results from the study reported in Fig. 1, prompted the measuring of the ratio between pairs of whole blood Se and plasma Se of all the trials according to time after onset of Se supplementation (Fig. 2).

The ratios between whole blood Se and plasma Se increased to reach an apparent steady-state at approximately 50 days after onset of supplementation for the inorganic sources and 70 days for the organic sources. At steady-state the ratios between blood and plasma Se concentrations were 2.7:1 $\left(\mathrm{R}^{2}=0.66\right)$ when organic Se sources were fed and 2.3:1 $\left(\mathrm{R}^{2}=0.55\right)$ when the dietary Se was mainly in the inorganic form. These results suggest that plasma Se reaches a steady-state within a few days of supplementation, while that of whole blood reaches a steady-state only at 50-70 days after commencement of the constant inclusion of Se in the diet.

These ratios remained relatively constant even though dietary levels of Se in the treatments ranged from 0.07 $\mathrm{mg} / \mathrm{kg}$ to $6.4 \mathrm{mg} \mathrm{Se} / \mathrm{kg} \mathrm{DM}$. However, within treatment, Se concentration in the diet remained relatively constant for the duration of the study. Whether this would be the case where Se requirements fluctuate depending on the stage of reproduction, for instance in dairy cows, is debatable. Thompson and Ellison (1993) pointed out that the relationship between serum and blood Se concentration will not be linear in animals subjected to changes in dietary Se intake or at different stages of the Se supplementation programme.

Since whole blood and plasma Se concentrations seem to continue to increase with time after commencement of supplementation (Knowles et al., 1999; Cristaldi et al., 2005), the time of reaching steady-state is probably somewhat arbitrary. However, in the present investigation, the ratios between Se in whole blood and plasma showed quite a distinct pattern of reaching a stabilizing point at between 50 and 70 days after commencement of Se supplementation.

The ratio between whole blood Se and serum/plasma Se concentrations has been reported in a number of studies 


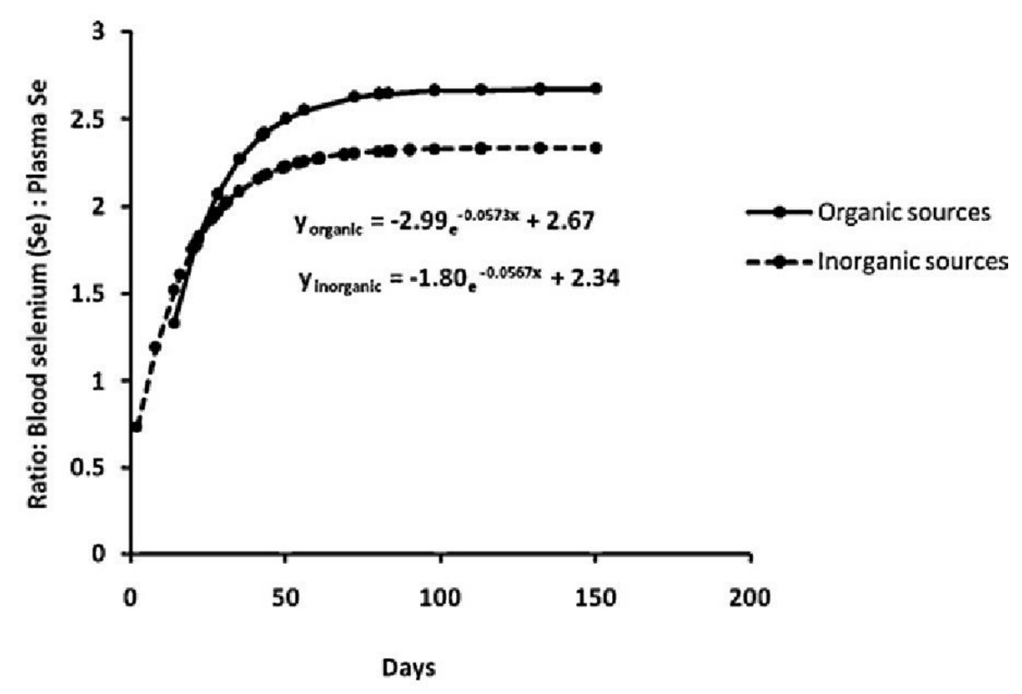

Fig. 2. Changes in the ratio between selenium concentrations in whol blood and plasma after commencement of selenium supplementation.

in the literature, and has varied substantially. Ulrey (1987) stated that the Se concentration in whole blood is between $10 \%$ and $50 \%$ higher than that in plasma. Maas et al. (1992) reported blood Se to serum Se ratios of 2.41 $\pm 0.81\left(\mathrm{R}^{2}=0.77\right)$ and $2.25 \pm 1.12\left(\mathrm{R}^{2}=0.82\right)$, depending on the analytical techniques used. These authors stated that these ratios are not constant over a range of blood Se concentrations. Stowe and Herdt (1992) quoted whole blood to serum ratios of $c a$. 1 in swine, 1.4-1.5 in horses and llamas, 2.5 in dairy cattle and 4 in sheep, particularly neonates, suggesting species differences in this ratio. They pointed out that these ratios would initially be narrow after an increase in oral Se intake and widen on cessation of Se supplementation. Pherson (1993) found that whole blood values are 1.5-2.5 times higher than those of serum or plasma, and for dairy cows Whelan et al. (1994) calculated that plasma Se constituted about 33\% of Se in whole blood. Waldner et al. (1998) gave ratios of 3.3:1 from one laboratory and 1.8:1 from others. Cristaldi et al. (2005) found that except at the highest level of dietary Se (10 ppm), blood Se concentration was ca. 2-3 times higher than serum Se concentration.

Using all the Se concentrations of plasma and blood collected after 50 days of commencement of supplementation, the concentration in plasma Se was calculated as a proportion of its corresponding whole blood Se concentration. When whole blood concentrations were $>100 \mathrm{ng} / \mathrm{g}$ this fraction (mean \pm standard deviation, SD) was $0.445 \pm 0.071$ $(n=63)$ for the inorganic sources, and $0.410 \pm 0.078(n=21)$ for the organic sources. Interestingly, when whole blood Se concentration was below $100 \mathrm{ng} / \mathrm{g}$ the mean was very similar to the above, at $0.470 \mathrm{mg} / \mathrm{g}$ but a much higher $\mathrm{SD}$ of \pm 0.174 ( $\mathrm{n}=25$, mainly in the form of natural Se in the feed). These ratios include data from the depletion treatments in the four trials referred to, which include the three grazing trials. This might indicate that daily Se intakes could have fluctuated in the grazing situation and that relatively small variations in Se intake would represent a proportionally higher percentage relative to intake than at the higher Se intakes.

\subsection{Effects of dietary composition and source of selenium}

Although the composition of the diets used in the different experiments in the current study differed substantially (Table 1) the $R^{2} s$ of the graphs within selenium source were relatively high. This suggests that the conclusions made should be fairly generally applicable.

The form in which Se is absorbed, plays a significant role in its metabolism in the body. When Se is fed as an inorganic source of Se, such as sodium selenite, it is incorporated in molecules where Se is an active ingredient, such as in GSH-Px and a number of other molecules (Whanger, 2002). Except for that, very little Se is stored in the body. On the other hand, the Se in plant food sources is mainly in organic forms, a large proportion of which is selenomethionine (Whanger, 2002). Organic Se sources supply the element to molecules containing Se, but selenomethionine is also deposited in bodily protein by substituting methionine in protein molecules. Consequently, the Se concentration in tissues and bodily fluids is higher when $\mathrm{Se}$ is fed in the organic form compared to the inorganic form (Beilstein and Whanger, 1986; Van Ryssen et al., 1989). Using the results from 12 studies on dairy cows where both organic and inorganic Se sources were supplemented, Weiss (2003) calculated that the Se concentration in whole blood is approximately $18 \%$ higher in whole blood when organic Se was fed, than when 
inorganic Se is fed. This difference is evident, though less pronounced, in plasma (Van Ryssen et al, 1989). From this it can be deducted that the ratio of Se in whole blood vs plasma should be higher when organic Se is fed as compared to inorganic Se.

Therefore, the differences in the whole blood Se to plasma Se ratios between the organic and inorganic sources of Se, as recorded in Fig. 2, could be expected. Because of the limited number of ratios recorded for organic Se sources and the fact that the data were not comparable, these ratios were not compared statistically, though the slopes of the two curves did not differ significantly.

\subsection{Ratio during depletion}

Wright (1965) observed that plasma Se concentration decreased exponentially after a single dose of ${ }^{75}$ Se. Langlands et al. (1991) concluded that the two indices of Se status of the animal, whole blood and plasma Se, do not behalf similarly: Both are elevated following supplementation but thereafter plasma Se concentration falls exponentially and more rapidly than those in whole blood. Stowe and Herdt (1992) stated that this ratio would initially be narrow after an increase in oral Se intake and initially be wide on cessation of Se supplementation.

In the current study, results from only four treatments were available to calculate changes in blood and plasma Se concentrations during a stage of depletion. However, at the start of the trials the sheep in all four studies were already marginal deficient. An exponential drop in plasma Se concentration, as observed by Wright (1965), could therefore not be expected. The Se concentrations in plasma and whole blood continued to decrease as the trials progressed, though the decline in whole blood Se was much steeper than in plasma Se concentration. This could be expected when the process of depletion of Se from erythrocyte is still in progress. However, the number of observations was too low to calculate the ratio between whole blood to plasma Se when the animals were Se deficient.

\subsection{Short term vs. long term predictors of Se status}

The current results support the accepted notion that plasma/serum Se is a short-term predictor of Se status of animals, because steady-state seems to be reached within 4 days of commencement of Se supplementation. However, if Se intake is unchanged over a period, plasma Se concentration would be effective as a long-term predictor of Se status.

Although the selenium concentration in whole blood is described as a long-term predictor of Se status, from the present study it is clear that whole blood selenium concentrations reach steady-state only at $>50$ days after commencement of supplementation. The present results suggest that whole blood Se would not be an accurate predictor of Se status during the $c a$. 50 days before steady-state is reached. A conclusion would be that whole blood Se concentration should be used only after the animal has been on a specific diet for about 2 months.

This general concept is accepted in the literature: Van Saun (1990) stated that if an animal is maintained on a consistent Se intake over a period of months, all tests will be of equal accuracy in defining Se status. However, if an animal receives differing levels of dietary Se, interpretation of the animal's Se status may fluctuate based on the assay used. Ulrey (1987) pointed out that it may be nearly impossible to establish the Se status of an individual with certainty unless the previous dietary history is taken into account.

\section{Conclusion}

It can be concluded from these results that if Se consumption were constant, plasma Se concentration would be maintained at a relatively constant level from day 4 onwards, while the relationship between the Se concentrations in whole blood and plasma would reach a plateau only at 50-60 days after commencement of Se intake. This suggested that at a ratio of $<2: 1$ plasma Se has reached steady-state, but whole blood Se has not. Therefore, plasma/serum Se concentration would be more reliable in reflecting Se status of the animal than Se in whole blood. This would be the case for up to 50 days after supplementation started. Whole blood to serum (plasma) Se ratios of between 2:1 and 3:1 would indicate that the Se in both whole blood and plasma is in a steady-state and either parameter could be used to assess the Se status of the animals.

At least at the early stages of Se depletion the ratio of $>3: 1$ could be expected. However, the data in the present study were too few to draw any conclusions on what the situation would be when changes due to the depletion of Se have been stabilized, or what the whole blood to plasma Se ratio would be when the animal is in a state of Se deficiency.

\section{Acknowledgements}

The authors wish to express their appreciation, and acknowledge the contribution of the postgraduate students from whose dissertations much of the data were obtained, especially where they were tasked to perform extra analyses which could be used in this investigation. 


\section{References}

Beilstein, MA, Whanger, P.D, 1986. Chemical forms of selenium in rat tissues after administration of selenite or selenomethionine. J. Nutr. 116,1711-1719.

Boldizarova, K., Gresakova, L, Faix, S., Levkut, M., Leng, L, 2003. Urinary selenium excretion in selenite-loaded sheep and subsequent Se dynamics in blood constituents. Reprod. Nutr. Dev. 43,385-393.

Cristaldi, LA, McDowell, L.R., Buergelt, CD., Davis, PA, Wilkenson, N.S., Martin, F.G., 2005. Tolerance of inorganic selenium in wether sheep. Small Rumin. Res . 56, 205-213.

Cronjé, M.C.., 2004. Die waarde van spoorelementaanvulling aan skape op'n subonderhoudsrantsoen. M. Sc. Agric. dissertation, University of Pretoria, Pretoria, South Africa. (in Afrikaans).

Gerloff, B.J. 1992. Effect of selenium supplementation on dairy cows. J. Anim. Sci. 70, 3934-3940.

Hall, J.O., 2006 . Assessing mineral status of dairy cattle. In: Inter-Mountain Nutritional Conference, January 2006 , Salt Lake City, pp. 33-41.

Hartmann, F.D., 1994. The effect of dietary sodium bicarbonate supplementation on the metabolism of selenium and copper in sheep. M.Sc . Agric Dissertation, University of Natal, Pietermaritzburg, South Africa.

Hartmann, F., Van Ryssen, J.B.J., 1997. Metabolism of selenium and copper in sheep with and without sodium bicarbonate supplementation. J. Agric. Sci., Camb. 128,357-364.

Jansen van Rensburg, C, 2000. Die effek van organiese en anorganiese selenium op die immuunsisteem van skape. M.Sc. Agric. Dissertation. University of Pretoria, South Africa. (in Afrikaans).

Kaneko,J.J. 1980. Clinical Biochemistry of Domestic animals, 3rd ed. Academic Press, NY, p. 134.

Kincaị, R.L., 1999. Assessment of trace mineral status of ruminants: a review. Proc. Am. Soc. Anim. Sci. 1-10.

Kincaid, R., 2008. Variability in the concentration of minerals in blood of peripartum cows. In: 2008 Pacific Northwest Animal Nutrition Conference, Tacomo, Washington, USA, 7-9 October 2008, pp. 133-142.

Knowles, S.O., Grace, N.D., Wurms, K., Lee,J., 1999. Significance of amount and form of dietary selenium on blood, milk and casein selenium concentrations in grazing cows. J. Dairy Sci. 82,429-437.

Koh, T.S., Benson, T.H., 1983. Critical re-appraisal of fluorometric method for determination of selenium in biological materials. J. Assoc. Off. Anal. Chem. 66, 918-926.

Langlands, J.P., Donald, G.E., Bowles, J.E., Smith, A.J., 1991. Subclinical selenium insufficiencies 1. Selenium status and the response in liveweight and wool production of grazing ewes supplemented with selenium. Aust. J. Exp. Agric. 31, 25-31.

Maas, J., Galey, F.D., Peauroi, J.R., Case, J.T., Littlefield, E.S., Gay, C.C., Koller, L.D., Crisman, R.O., Weber, D.W., Warner, D.W. Tracy, M.L., 1992. The correlation between serum and blood selenium in cattle.' J. Vet. Diagn. Invest. 4, 48-52.

Maas, J., Galey, F.D., Peauroi, J.R., Case, J.T., 1993. Reply: blood selenium or serum selenium? J. Vet. Diagn. Invest. 5,146-147.

Mavimbela, D.T., 2000. The nutritional value of broiler litter as a feed source for sheep during periods of feed shortage. PhD Thesis, University of Pretoria Pretoria, South Africa.

Nicholson, J.E.G., Allen, J.G., Bush, R.S., 1991. Comparisons of responses in whole blood and plasma selenium levels during selenium depletion and repletion of growing cattle. Can. J. Anim. Sci. 71, 925-929.

Payne, R.W., Murray, D.A., Harding, S.A., Baird, D.B., Soutar, D.M., 2011. GenStat ${ }^{\circledR}$ for Windows ${ }^{\mathrm{TM}} 14$ th Edition, Introduction. VSN International, UK.

Pherson, B., 1993. Diseases and diffuse disorders related to selenium deficiencies in ruminants. Norwegian J. Agric. Sci., Suppl. 11, 79-93.

Puls, R., 1994. Mineral Levels in Animal Health. Diagnostic Data, 2nd ed. Sherpa Int, Canada.

Samuels, M.L., 1989. Statistiç for the Life Sciences. Collier MacMillan Publishers, London.

SAS, 2012. Statistical Analysis Systems, Users Guide. Statistics Version 9. 3. SAS Institute Inc, Cary, N.C. USA.

Stowe, H.D., Herdt, T.H., 1992. Clinical assessment of selenium status of livestock. J. Anim. Sci. 70,3928-3933.

Taylor, J.B., 2005. Time-dependent influence of supranutritional organically bound selenium on selenium accumulation in growing wether lambs. J. Anim. Sci. 83,1186-1193.

Thompson, K.G., Ellison, R.S., 1993. Blood selenium or serum selenium. Letters to Editor. J. Vet. Diagn. Invest. $5,145-146$. Ulrey, D.E., 1987. Biochemical and physiological indicators of selenium status in animals. J. Anim. Sci. 65,1712-
1726 .

Underwood, E.J., Suttle, N.F., 1999. The Mineral Nutrition of Livestock, 3rd ed. CABI Publishing.

Van Ryssen, J.B.J., Deagen, J.T., Beilstein, MA, Whanger, P.D., 1989. Comparative metabolism of organic and inorganic selenium in sheep. J. Agric. Food Chem. 37,1358-1363.

Van Ryssen, J.B.J., 1995. Effect of different conditions in the rumen of sheep on the metabolism of selenium in the organic and inorganic form. Department of Animal \& Poultry Science, University of Natal, South Africa. Technical Report to Alltech Inc., Lexington, K.Y., USA.

Van Ryssen, J.B.J., Coertze, R.J., de Villiers, J.F., i 1999. Supplementation of selenium to sheep grazing kikuyu or ryegrass: II. Effect on selenium concentration in the grass and body tissues. S. Afr. J. Anim. Sci. 29, $145-153$.

Van Saun, R.J.. 1990. Rational approach to selenium supplementation essential. Feedstuffs 62 (3), $15-17$.

Waldner, C, C. Campbell, J., Jim, G.K., Guichon, P.T., Booker, C, 1998. Comparison of 3 methods of selenium assessment in cattle. Can. Vet. J. 39, 225-231.

Weiss, W.P., 2003. Selenium nutrition of dairy cows: comparing responses to organic and inorganic selenium forms. Nutritional Biotechnology in the Feed and Food Industry. In: Lyons, T.P., Jacques, K.A. (Eds.), Proceedings of Alltech's 19th Annual Symposium. Nottingham University Press, Ú, pp. 333-343.

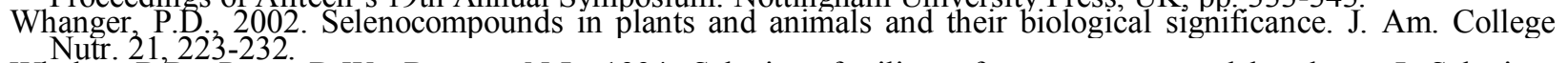

Whelan, B.R.; Peter, D.W., Barrow, N.J., 1994. Selenium fertilizers for pastures grazed by sheep. I. Selenium concentrations in whole blood and plasma. Aust. J. Agric. Res. 45, 863-875.

Wright, P.L., 1965. Life span of ovine erythrocytes as estimated from selenium-75 kinetics. J. Anim. Sci. 24, 546550 . 